\title{
A Call for Standardized Reporting of Adverse Events
}

Fankhauser, Christian D ; Wettstein, Marian Severin ; Pedregal, Manuel ; Clarke, Noel W ; Sweeney, Christopher J

DOI: https://doi.org/10.1016/j.eururo.2020.06.052

Posted at the Zurich Open Repository and Archive, University of Zurich ZORA URL: https://doi.org/10.5167/uzh-188646

Journal Article

Accepted Version

Originally published at:

Fankhauser, Christian D; Wettstein, Marian Severin; Pedregal, Manuel; Clarke, Noel W; Sweeney, Christopher J (2020). A Call for Standardized Reporting of Adverse Events. European Urology:? DOI: https://doi.org/10.1016/j.eururo.2020.06.052 
Example 1: fatigue any grade

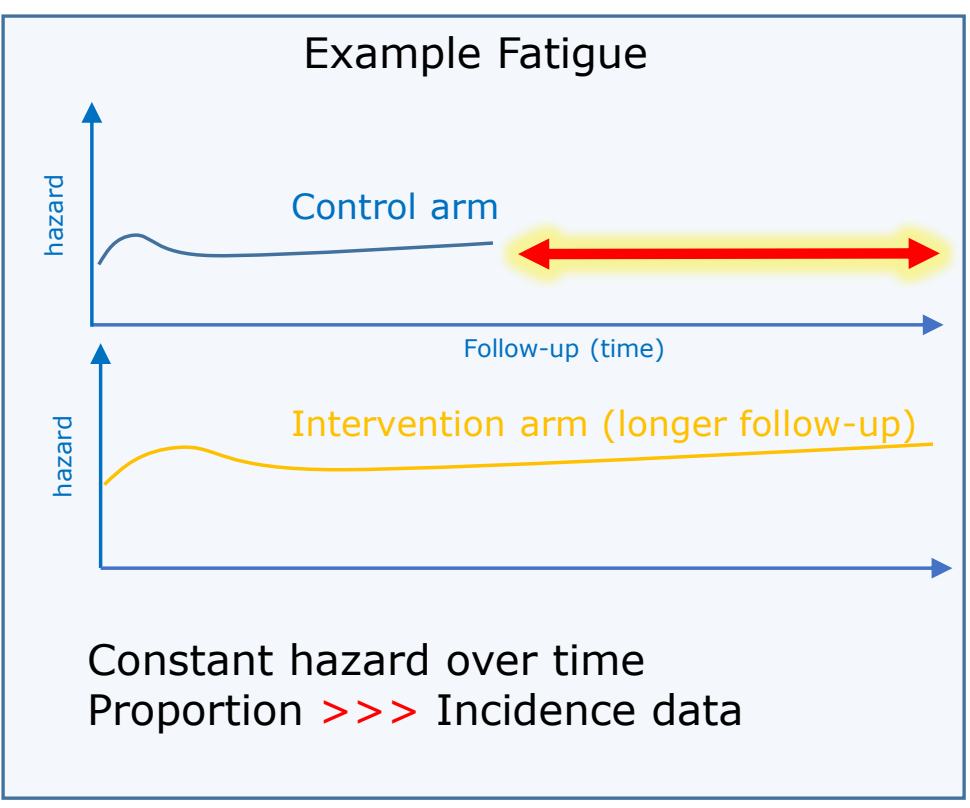

\section{Example 2: hypokalemia any grade}

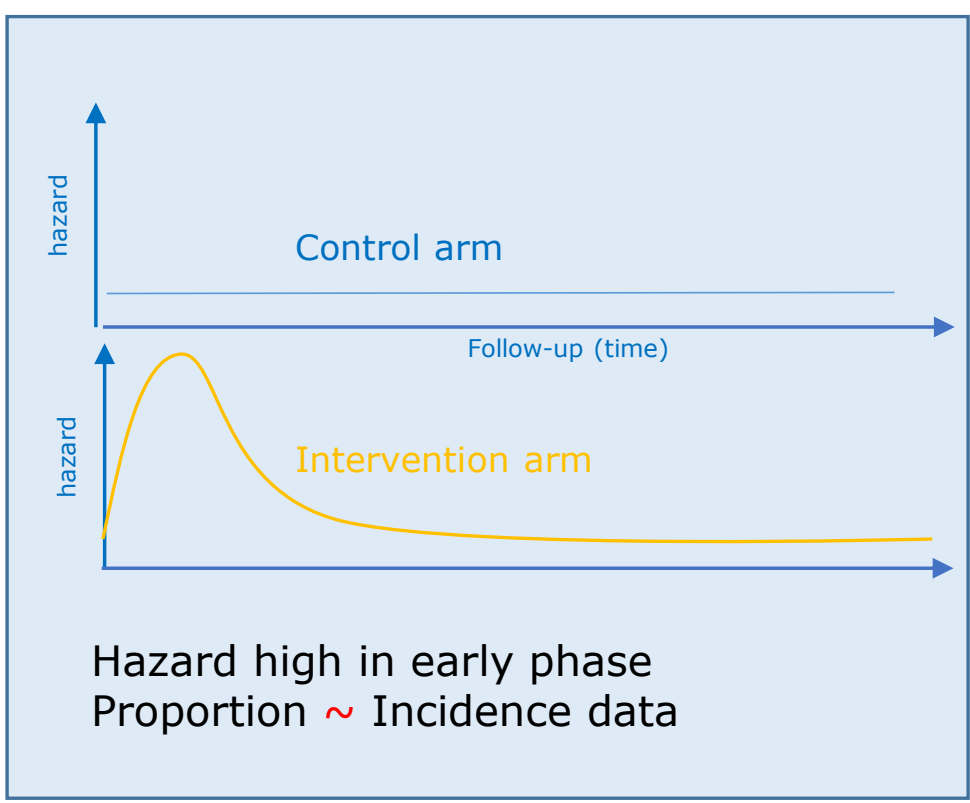

Comparison any grade fatigue for enzalutamide arms compared to control arms Any-grade fatigue Proportion

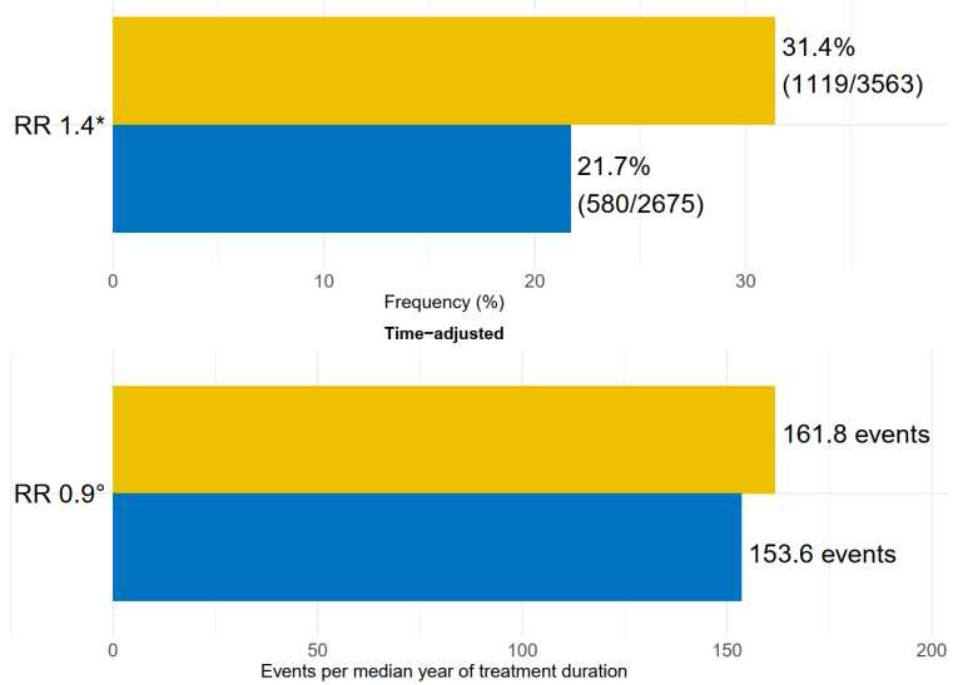

Comparison any grade hypokalemia for abiraterone arms compared to control arms Any-grade hypokalemia

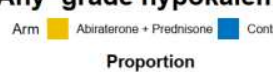

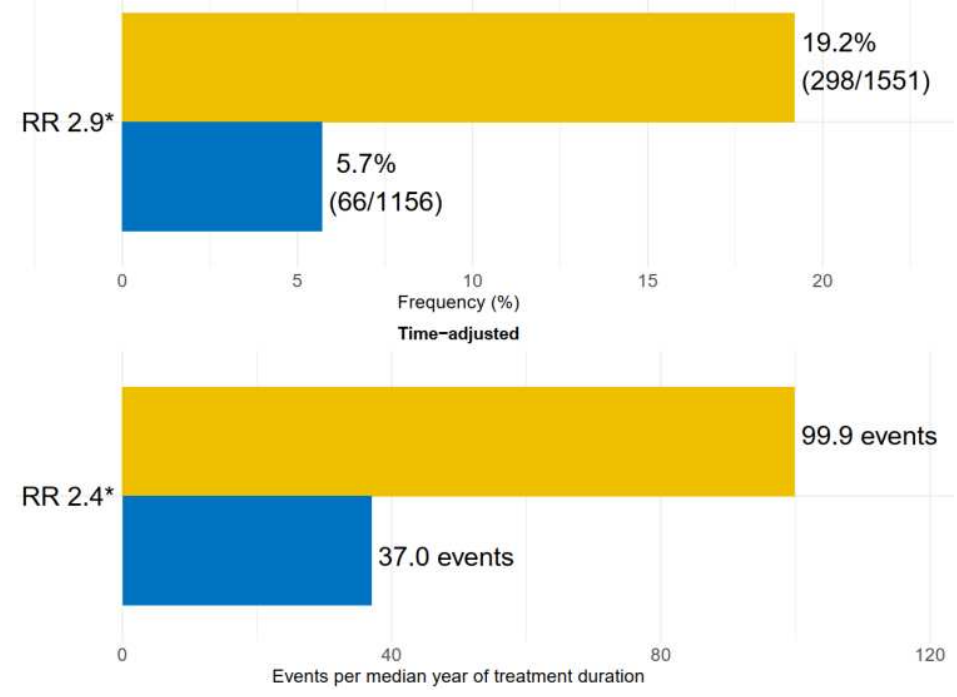

